\title{
Research on Motivational Factors and Countermeasures of Knowledge Employees in Internet Company
}

\author{
Chenxi Zhang \\ School of Management, Wuhan University of Technology, Wuhan, 430000, China
}

Keywords: Knowledge employees, Motivational factors, Internet company.

\begin{abstract}
At present, the knowledge employee has become the core part of enterprise human resources, and is the most important driving force for enterprise to create value. Every internet company has many knowledge workers. It is an important issue to effectively motivate the knowledge workers in internet enterprises. This paper analyzes the motivational factors of knowledge employees in internet companies, including cultural identity, participative management and challenging task, and gives countermeasures from the perspectives of individual development, job security and enterprise management to provide some references for the relative researchers.
\end{abstract}

\section{Introduction}

Knowledge workers are a special group, which has its own unique characteristics. They differ from non-knowledge workers in cognitive ability, personal needs, values and work style. Compared with traditional enterprises, knowledge workers in China's internet companies have their own characteristics. Knowledge workers have a strong ability to innovate and help internet companies gain competitive advantage in a changing market environment. This requires internet companies to combine different characteristics of knowledge workers and adopt different incentive strategies to motivate them. The knowledge staff refers to the education and training for too long a time to accept, with high quality professional knowledge and ability, can carry their own knowledge of science and technology in the internet industry and have professional ability and quality of creative work of the people. Knowledge of internet enterprise employees generally have higher quality of them well educated have more internet technology and master the skills and knowledge of enterprise core and key customer relationship. Compared with traditional enterprises, industrial internet companies have such characteristics as short technology life cycle and fast product update. Faced with these challenges, internet enterprise knowledge workers need to change in a variety of new problems that may arise. At present, there are many problems in the incentive mechanism of knowledge workers in China's internet companies. Some internet companies only pay attention to incentive pay. Relying solely on higher salaries and benefits does not solve the problem, but bad handling can lead to a sense of unfairness inside. This may have a negative effect on employees with relatively small incomes. At present, the incentive demand of knowledge workers shows a trend of constant development. Traditional incentives have been unable to meet their needs. In the internet enterprises, it is an urgent problem to be solved to effectively motivate knowledge workers.

\section{Motivational Factors of Knowledge Employees in Internet Company}

Cultural Identity. Knowledge workers pay more attention to the company's prospects. In the internet enterprise, the enterprise culture reflects the enterprise leader's values and management concepts. It forms a corresponding atmosphere in turn in the development of the enterprise, which will affect the enterprise management. In the management of knowledge workers, we should pay attention to the needs of knowledge workers in internet companies, create a relaxed cultural atmosphere, and promote the integration of employees and enterprises. On the one hand, the enterprise should allow employees to make mistakes, knowledge workers love some creative and challenging work, in this work under the environment of knowledge workers should be allowed to 
make mistakes, only in a relaxed atmosphere to produce more inspiration, give full play to the ability of employees. Especially the internet enterprise scientific and technical personnel, to achieve innovation and patented technology, need to continue efforts and try to employees, encourage and support appropriate to this kind of person, in addition to the above hardware support, but also need to create achievement culture and support culture in the integration of corporate culture, innovation incentive of knowledge workers. Establish a good corporate culture, cultivate the internet enterprise knowledge workers corporate culture identity. The enterprise culture is gradually formed in the development of practice has its own characteristics of the enterprise values, beliefs, pursuit and conduct internet business members, is one of the essential content of modern enterprise development. Enterprise culture plays an important role in the organization. Good corporate culture can create a harmonious atmosphere of the organization. The atmosphere is conducive to mobilize the enthusiasm of internet enterprise employees, improving the satisfaction and sense of achievement of the knowledge employees.

Participative Management. Participation management refers to employees and subordinates to participate in the decision-making process of organization and management work in different degrees, let subordinates and employees and business managers in the status of research and discussion of major issues in the organization of equality, they can feel superior to the trust, and thus experience closely related interests and organize their own development and have a strong sense of responsibility. At the same time, participation in management provides employees with an opportunity to get the attention of others, thereby giving them a sense of accomplishment. Employees are motivated to be able to participate in discussions about their own problems. Participation in management not only gives incentives to individuals, but also provides guarantee for the realization of organizational goals. The way to participate in management attempts to influence organizational performance and employee job satisfaction by increasing the input of organizational members to decision-making process. The amount of power granted to employees can vary greatly from simply allowing them to input a certain amount of information for managers to make decisions, to collectively making decisions among employees, and to making decisions by employees themselves. The form of participation in management is varied, and it should be used flexibly, not only to arouse the enthusiasm of employees, but also to make effective participation in management. Internet companies should allow employees to have decision-making power. For example, some employees participate in or attend important meetings of the company, and know how the company's important decisions are drawn up, the company's next goal, targeted work. Internet companies want employees to have a sense of participation. The internet enterprise can motivate employees through the employee stock ownership form, let employees participate in the company management, so that employees in power, improve accountability, participation directly to the company's management, enhance the sense of ownership. In short, through participative management, knowledge employees enhance the sense of responsibility and the company enhance the sense of identity, achieving win-win results of the company and employees.

Challenging Task. The assignment of the challenging work to the knowledge employees can fully stimulate the potential of staff, enhance their sense of pride, sense of achievement, self-confidence and enthusiasm for work, also contributed to the growth of knowledge, improve skills, enhance comprehensive quality. As the leader, we should do our best to provide some challenging work for our subordinates, so that employees will feel a certain challenge every day. Constantly set goals for knowledge workers. This goal is to let employees through their own efforts can be completed, so that employees will be able to achieve a high degree of satisfaction. The process by which employees accomplish their goals is the process of challenging themselves and fully exploiting their potential. This is also the process of promoting the development of enterprises with maximum efficiency. At the same time, the company must establish scientific and reasonable and has a fully humanized appraisal system, to complete the objectives and tasks of excellent employees to give appropriate incentives, through the most intuitive performance of staff assessment, and as a driving force, and constantly promote the improvement of work and improve its employees. Leaders should allow employees to achieve a sense of achievement in their gradual success, so that enterprises will continue to grow in 
the gradual growth of employees. Internet companies can train their employees and encourage employees to challenge their limits in the provision of innovative mechanisms and platforms. The enhancement of crisis awareness is an important step in creating an innovative culture. For the current chinese enterprises, facing various challenges, only to meet the crisis with greater competitiveness can we remain invincible. The motive force of innovation is crisis awareness, and the leadership of internet companies should often stimulate employees' sense of crisis, and encourage employees to accept challenges bravely. To give knowledge workers a certain scope of authority and freedom is necessary to form a spontaneous sense of innovation and challenge.

\section{Motivational Countermeasures of Knowledge Employees in Internet Company}

Motivate Knowledge Employees from the Perspective of Individual Development. According to the personality characteristics and job differentiation needs of knowledge workers, enterprise can provide related professional career courses for them. At the same time to provide employees with skills to improve their own training, enterprises set up career counseling room, to resolve staff concerns and questions. According to the goals and present situation of employees, the author analyzes and designs them, and provides personalized career planning services for employees, and fundamentally solves the confusion and uncertainty of employees' future career. Occupation career planning system, which can effectively solve the problem of employee goals and corporate vision is not uniform, can not only improve the employees a sense of belonging and attachment, but also can enhance the competitiveness of enterprises, promote enterprise development. Job rotation will have a positive impact on employee growth. Fast update the knowledge in the internet industry, only by constantly learning new knowledge, to keep up with the pace of social progress to promote the enterprise toward the front row of the right direction of development, organize staff training and learning, not only to enhance the staff's personal quality, but also imperceptible to promote the development of the enterprise. The knowledge staff at work in the hope to take a fresh and challenging work, when knowledge workers think that there is no novelty and challenge, the enterprise can be adjusted to work through adjusting the position, rotation, rich work form, and make them accessible to interested in work and improve the understanding of things, the staff of the enterprise work. The internal promotion is easier to integrate into the team, more stable, fair and reasonable internal promotion mechanism. It can not only stimulate the employee positive, but can also boost team style, improve team performance, forming a virtuous cycle of competition.

Motivate Knowledge Employees from the Perspective of Job Security. The salary and welfare factors can play an important role in attracting, retaining and stimulating the potential of employees, enhancing the competitiveness of enterprises and achieving the strategic objectives of enterprises. As the salary does not only satisfy the material needs of knowledge workers, but also on behalf of the enterprise recognized for his work ability, while wages also represent his status in society, there is a person to meet the feelings inside. Therefore, enterprises must establish a set of effective compensation and welfare incentive system. Salary incentive is not the most important incentive factor for knowledge workers, but it still has great attraction for knowledge workers, including salary increase, commission, year-end bonus, stock options, various bonuses and allowances. In the internet this highly flattened enterprises, knowledge workers through efforts to get the chance of promotion is less and less, while maintaining the position level unchanged, give employees salary incentive to meet the needs of employees to respect appropriate, so that employees can also be motivated, stable staff continue to make contributions to the enterprise, salary incentive system and personal growth incentive system complement each other. Welfare incentive is a supplementary mechanism of salary incentive. Unlike salary, welfare is intangible security and service, including medical insurance, pension insurance, housing provident fund, paid vacation. Due to the difference of the personality and demand of each knowledge worker, the enterprise cannot set a fixed set of incentive scheme. The enterprise should establish a flexible incentive system, employees can through their own needs and preferences, choose a different combination of benefits. At the same time, enterprises should adjust 
the welfare system $t$ to meet the demands of staff to the maximum extent according to the needs and demands of employees periodically.

Motivate Knowledge Employees from the Perspective of Enterprise Management. The internet industry requires not only the ability of knowledge workers to handle complex tasks, but also that they need good interpersonal and communication skills to work together. Therefore, it is necessary to establish mutual communication, understanding and communication platform, to create an open and free atmosphere, and give them listen to the demands of space, strengthen the knowledge staff's emotional communication, promote their mutual respect and trust, so that employees feel from the care of others, resulting in the sense of belonging, inspire their creativity and the potential from the heart, to enhance the competitiveness of enterprises. Knowledge workers have strong personality and have their own unique opinions and needs in their jobs. Therefore, enterprises should fully consider the needs of employees and team needs when allocating their work. According to the employee's age, work experience, occupation career planning information, analysis of personal characteristics and style preferences, provide incentives and diversified suitable jobs for them at the same time, regular collection of work demands of employees, make the appropriate adjustments. Finally, create cohesive corporate culture. To create a cohesive business atmosphere is the most important unity of staff objectives and business goals, knowledge sharing, through regular business training, so that employees in improving the quality of enterprises the status quo of the development of attention at the same time, to enhance staff enthusiasm for innovation, grasp the direction of enterprise development, so that employees see the prospects for the development of enterprises that cause psychological resonance to ensure their loyalty. The employee participation in management can enhance communication and coordination within the organization. Employee involvement in management can improve employee motivation, especially when some of their important personal needs are met. In the practice of management, knowledge employees improve their ability and the status of enterprise management.

\section{Conclusion}

The ultimate aim of the research of motivational factors of knowledge employees in internet companies is to formulate scientific incentive policies to effectively motivate knowledge workers. This research puts forward a motivation improvement plan of knowledge employees of internet companies. The effects of these incentives need to be tracked and verified by empirical analysis.

\section{References}

[1] Hu Youxuan. Approach for Improving Performance of Knowledge-based Employees in an Enterprise [J]. Business Economy, 2017(3): 115-117.

[2] Wang Wenbo, Han Min, Lin Bo. An Empirical Study on Motivation and Hygiene Factor of Knowledge Workers - Based on Software Outsourcing Enterprise of Dalian [J]. Journal of Dalian University, 2012, 33(3): 82-87.

[3] Lu Jihua, Chen Lili, Zhao Xinan. Relationship Study on Perceived Organizational Support, Organizational Commitment Support and Engagement of Knowledge Employees [J]. 2013, 34(1): 147-153.

[4] Lu Yumei, Gao Peng, Gao Jie, Liu Suxia. A Research on Incentive Mechanism of the Knowledge Employee Responsibility Investment Under the Situation of Team Collaboration [J]. On Economic Problems, 2016(1): 100-107. 